J. Clin. Chem. Clin. Biochem.

Vol. 18, 1980, pp. 423-429

\title{
Harnstoff, Kreatinin, Harnstoff- und Kreatinin-Clearance: Untersuchungen an 25 gesunden Probanden über ein Jahr
}

\author{
Von C.-D. Koch, E. Arnst und K. Rommel \\ Abteilung für Klinische Chemie (Leiter: Prof. Dr. K. Rommel) der Universität Ulm
}

(Eingegangen am 7. Juli/31. Dezember 1979/19. Februar 1980)

Zusammenfassung: Bei 25 gesunden Probanden wurden über ein Jahr in monatlichen Abständen, im Mai und Novembèr täglich über eine Woche, die Konzentrationen von Kreatinin und Harnstoff im Serum und Urin bestimmt und die Harnstoff- sowie Kreatinin-Clearance berechnet. Es fanden sich geschlechtsabhängige Referenzbereiche, wobei die geringe longitudinale Variation der Kreatinin-Konzentration im Serum die Verwendung individueller Normwerte empfehlenswert macht. Die saisonalen Schwankungen der Harnstoff-Konzentration im Serum, der Ausscheidung von Harnstoff und Kreatinin sowie der Harnstoff- und Kreatinin-Clearance waren hochsignifikant. Die gleichsinnige Änderung der Kreatinin- und der Harnstoff-Clearance spricht für eine jahreszeitabhängige Variation der Nierenleistung.

\section{Urea and creatinine levels and clearances: Observations in 25 healthy subjects for one year}

Summary: The seasonal, intra- und interindividual variation of the creatinine and urea concentrations in serum and urine and the clearances of these compounds were examined monthly for one year in 25 healthy volunteers. In contrast to the other parameters (serum urea, clearance and excretion of creatinine and urea), the variations in serumcreatinine concentration were small and statistically unsignificant.

The variation of the urinary excretion and the clearance of creatinine and urea is due to seasonal variations in the output of the kidney.

\section{Einführung}

Die Kenntnis der intraindividuellen (longitudinalen) sowie der interindividuellen (transversalen) Streuung der Konzentration des Harnstoffs und des Kreatinins im Serum und der Clearance beider Substanzen ist in der Diagnostik der Nierenfunktion von Bedeutung. Ein circadianer Rhythmus von Harnstoff und Kreatinin besteht nach Knoll et al. (1) nicht. Langzeituntersuchungen über vier Monate ergaben eine intraindividuelle Variation der Kreatininkonzentration im Serum von $4 \%$, der Harnstoffkonzentration im Serum zwischen 11,9 und $14,2 \%$ (2). Für die Kreatininausscheidung im Urin und das Harn-Volumen wurde von Robertșon et al. (3) über ein Jahr keine signifikante Änderung beobachtet.

In der vorliegenden Arbeit wird untersucht, wie groß die Variation der Harnstoff- und Kreatininkonzżentration im Serum, deren Ausscheidung im Urin, sowie der Clearance dieser Metabolite über ein Jahr ist.

\section{Material und Methodik}

In dex Zeit zwischen dem 15. Januar und 15. Dezember 1978 wurde bei 25 Probanden (Ärte und Labor-Assistenten, Tab. 1) einmal monatlich, im Mai und November jeweils an füf aufeinanderfolgenden Tagen, morgens (8.00-9.00), nüchtern, nach 10 Minuten Sitzen, aus einer mit $10 \mathrm{~mm} \mathrm{Hg}$ über den diastolischen Blutdruck gestauten oberflächlichen Cubitalvene $40 \mathrm{ml}$ Blut mit Monovetten (Fa. Sarstedt, Nümbrecht) entnommen.

In den vorausgegangenen 24 Stunden ist der Urin (Zusatz: $5 \mathrm{ml}$ Thymollösung, $100 \mathrm{~g} / 1 \mathrm{Ethanol}(960 \mathrm{ml} / \mathrm{l}))$ gesammelt worden.

Tạb. 1. Anzahl, Alter, Größe und Gewicht der Probanden.

\begin{tabular}{llll}
\hline Probanden & Männer & Frauen & gesamt \\
\hline Anzahl & 16 & 9 & 25 \\
Alter & 36,2 & 33,8 & 35,3 \\
(Jahre) & $20-56$ & $25-52$ & $20-56$ \\
Größe & 177,4 & 166,8 & 173,6 \\
(cm) & $173-192$ & $160-173$ & $160-192$ \\
Gewicht & 73,7 & 59,7 & 68,6 \\
(kg) & $64-91$ & $50-68$ & $50-91$ \\
\hline
\end{tabular}


Die monatlichen Blutabnahmen erfolgten jeweils am gleichen Wochentag unter freier Diät. Die Gerinnung der Blutproben erfolgte bei Raumtemperatur, die Zentrifugation innerhalb einer Stunde, die Analytik (Doppelbestimmungen, seriell) nach maximal vier Stunden.

Die Bestimmung des Kreatinins ist kinetisch, modifiziert nach Jaffé (4-6) am Enzymautomaten Eppendorf 5020 (Netheler und Hinz, Hamburg) mit Reagenzien der Fa. E. Merck, Darmstadt (Nr. 3384) durchgefürt worden. Der Urin wurde hierfür $1+50$ mit bidest. Wasser verdünnt.

Die Harnstoffbestimmung erfolgte nach Berthelot mit Reagenzien der Fa. E. Merck (Nr. 3334) am C-4-A (Perkin-Elmer, Bodenseewerk). Der Urin wurde $1+20$ mit bidest. Wasser vorverdünnt.

In jeder Analy-senserie sind 15 Richtigkeitskontrollen (Precinorm U 719, Boehringer-Mannheim), je eine vor sowie nach jeder 5. Probandenprobe (Ergebnis: Tab. 2) und jeweils 2 weitere Richtigkeitsseren (Monitrol I 147, Merz und Dade, München; Monitrol II 51, Merz und Dade; Validate A 502, Goedecke, Freiburg; Kontrollogen L 3104, Behring, Marburg) in Einfachbestimmungen mitgeführt worden.

Die statistische Auswertung erfolgte durch Berechnung von Mittelwerten, Standardabweichungen und Variationskoeffizienten (7), Prüfung auf Normalverteilung (8) und mit varianzanalytischen Verfahren (Prüfung auf Gleichheit der Varianzen nach Cochran sowie Hartley, Varianzanalyse nach Link \& Wallace (7). Die Varianzanalyse trennt die Einflußgrößen in wirksame (wesentliche) und unwirksame (unwesentliche), indem sie eine beobachtete Gesamtvarianz in Anteile zerlegt, denen Ursachenkomplexe zugeordnet werden. Voraussetzung für die Durchführung der Varianzanalyse ist die Gleichheit der Varianzen der Einzelergebnisse.

Diese wurde geprüft nach:

$$
\frac{\mathrm{nR}\left(\overline{\mathbf{x}_{\mathbf{i}}}\right)}{\mathrm{R}_{\mathbf{i}}}>\mathrm{K}
$$

wobei $n=$ Umfang der Stichprobe, $R\left(\overline{\mathbf{x}}_{\mathbf{i}}\right)=$ Spannweite der Mittelwerte und $\mathbf{R}_{\mathbf{i}}=$ Spannweiten der Einzelgruppen sind. Die Nullhypothese $\mu_{1}=\mu_{2}=\ldots \mu_{K}$ wird zugunsten der Alternativhypothese nicht alle $\mu_{i}$ sind gleich, verworfen, sobald der errechnete Wert größer als der kritische Wert $\mathrm{K}$ ist. Multiple Ver-

Tab. 2. Angaben zur Qualitätskontrolle:

Prozentuale Abweichung des Istwertes vom Sollwert (Precinorm U, Charge 719, Sollwert Harnstoff $7,56 \mathrm{mmol} / \mathrm{l}$, Kreatinin $134 \mu \mathrm{mol} / \mathrm{l}$ ) und prozentualer Variations-Koeffizient (VK \% Serie) aus jeweils $15 \mathrm{Be}$ stimmungen am Untersuchungstag der Langzeitstudie sowie Variations-Koeffizient von Tag/Tag (\%) aus 254 Arbeitstagen.

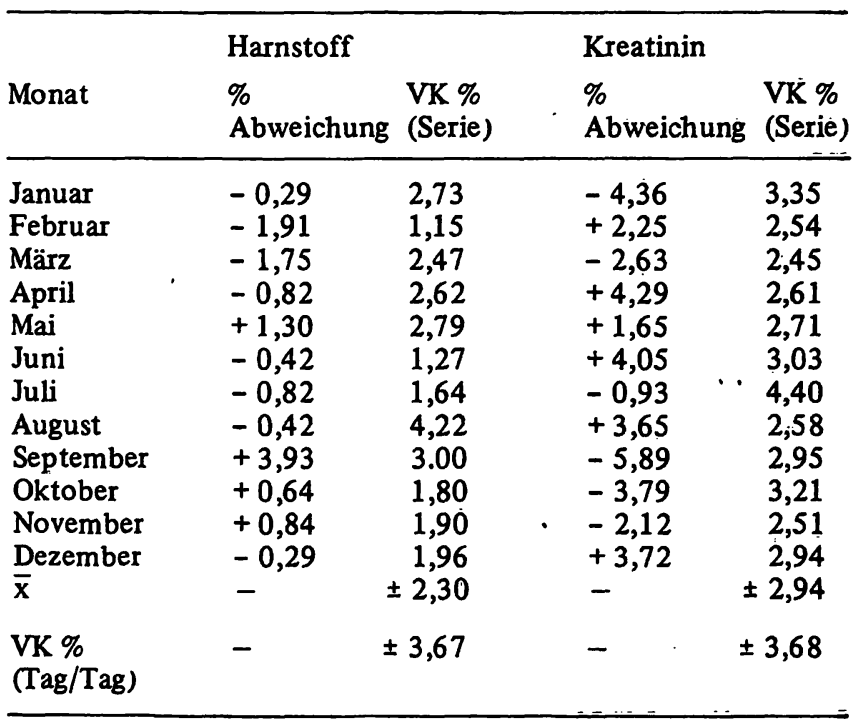

gleiche von Mittelwerten mit dem Mittelwertsunterschied D̂ sind auf dem verwendeten Niveau signifikant wenn:

$$
\hat{D}>\frac{K \Sigma R_{\mathbf{i}}}{n}
$$

\section{Ergebnisse und Diskussion}

Die Analysenergebnisse waren nach Péarson \& Stephens (8) mit $95 \%$ Wahrscheinlichkeit normal verteilt. Es konnte daher der interindividuelle, transversale Jahres-

Tab. 3. Interindividueller J̦ahres-Mittelwert und Standardabwei-

\begin{tabular}{|c|c|c|c|c|c|}
\hline & Kenngröße & & $\overline{\mathbf{x}}$ & $s$ & $\overline{\mathrm{x}} \pm 2 \mathrm{~s}$ \\
\hline \multirow[t]{2}{*}{ Serum } & $\begin{array}{l}\text { Harnstoff } \\
(\mathrm{mmol} / \mathrm{l})\end{array}$ & $\begin{array}{l} \\
9 \\
\text { ge- } \\
\text { samt }\end{array}$ & $\begin{array}{l}6,03 \\
5,17 \\
\left.5,69^{*}\right)\end{array}$ & $\begin{array}{l}1,26 \\
1,10 \\
1,27\end{array}$ & $\begin{array}{l}3,51-8,55 \\
2,97-7,37 \\
3,15-8,23\end{array}$ \\
\hline & $\begin{array}{l}\text { Kreatinin } \\
(\mu \mathrm{mol} / 1)\end{array}$ & $\begin{array}{l}\delta \\
q \\
\text { ge- } \\
\text { samt }\end{array}$ & $\begin{array}{l}78,3 \\
65,1 \\
\left.73,2^{*}\right)\end{array}$ & $\begin{array}{r}8,60 \\
7,72 \\
10,51\end{array}$ & $\begin{array}{ll}61,1 & -95,5 \\
49,7 & -80,5 \\
52,2 & -94,2\end{array}$ \\
\hline \multirow[t]{8}{*}{ Urin } & $\begin{array}{l}\text { Harnstoff } \\
(\mathrm{mmol} / \mathrm{d})\end{array}$ & $\begin{array}{l}0 \\
q \\
\text { ge- } \\
\text { samt }\end{array}$ & $\begin{array}{l}325,8 \\
257,4 \\
\left.299,5^{*}\right)\end{array}$ & $\begin{array}{r}115,0 \\
83,0 \\
108,9\end{array}$ & $\begin{array}{ll}95,8 & -556 \\
91,4 & -435 \\
81,7 & -517\end{array}$ \\
\hline & $\begin{array}{l}\text { Kreatinin } \\
(\mathrm{mmol} / \mathrm{d})\end{array}$ & $\begin{array}{l}\text { o } \\
q \\
\text { ge- } \\
\text { samt }\end{array}$ & $\begin{array}{c}13,80 \\
9,59 \\
\left.12,18^{*}\right)\end{array}$ & $\begin{array}{l}4,22 \\
1,97 \\
4,07\end{array}$ & $\begin{array}{l}5,36-22,2 \\
5,65-13,5 \\
4,04-20,3\end{array}$ \\
\hline & $\begin{array}{l}\text { Kreatinin/ } \\
\text { individ. Kör- } \\
\text { perober- } \\
\text { fläche } \\
(\mathrm{mmol} / \\
\mathrm{d} \cdot \mathrm{m}^{2}\end{array}$ & $\begin{array}{l}\delta \\
q \\
\text { ge- } \\
\text { samt }\end{array}$ & $\begin{array}{l}7,24 \\
5,72 \\
\left.6,68^{*}\right)\end{array}$ & $\begin{array}{l}2,21 \\
1,18 \\
2,23\end{array}$ & $\begin{array}{l}2,82-11,7 \\
3,36-8,1 \\
2,22-11,1\end{array}$ \\
\hline & $\begin{array}{l}\text { CLRS } \\
\text { Harnstoff } \\
(\mathrm{ml} / \mathrm{s})\end{array}$ & $\begin{array}{l}\delta \\
\$ \\
\text { ge- } \\
\text { samt }\end{array}$ & $\begin{array}{l}0,64 \\
0,61 \\
0,63\end{array}$ & $\begin{array}{l}0,24 \\
0,21 \\
0,23\end{array}$ & $\begin{array}{l}0,16-1,12 \\
0,19-1,03 \\
0,17-1,09\end{array}$ \\
\hline & $\begin{array}{l}\text { CĹRS } \\
\text { Kreatinin } \\
(\mathrm{ml} / \mathrm{s})\end{array}$ & $\begin{array}{l}0 \\
\wp \\
\text { ge- } \\
\text { samt }\end{array}$ & $\begin{array}{l}2,07 \\
1,73 \\
\left.1,94^{*}\right)\end{array}$ & $\begin{array}{l}0,63 \\
0,42 \\
0,58\end{array}$ & $\begin{array}{l}0,81-3,33 \\
0,89-2,57 \\
0,78-3,10\end{array}$ \\
\hline & $\begin{array}{l}\text { CLRM } \\
\text { Harnstoff } \\
(\mathrm{ml} / \mathrm{s})\end{array}$ & $\begin{array}{l}0 \\
\& \\
\text { ge- } \\
\text { samt }\end{array}$ & $\begin{array}{l}0,58 \\
0,63 \\
0,60\end{array}$ & $\begin{array}{l}0,21 \\
0,22 \\
0,22\end{array}$ & $\begin{array}{l}0,16-1,00 \\
0,19-1,07 \\
0,16-1,04\end{array}$ \\
\hline & $\begin{array}{l}\text { CLRM } \\
\text { Kreatinin } \\
(\mathrm{ml} / \mathrm{s})\end{array}$ & $\begin{array}{l}\delta \\
q \\
\text { ge- } \\
\text { samt }\end{array}$ & $\begin{array}{l}1,86 \\
1,79 \\
1,84\end{array}$ & $\begin{array}{l}0,56 \\
0,44 \\
0,52\end{array}$ & $\begin{array}{l}0,74-2,98 \\
0,91-2,67 \\
0,80-2,88\end{array}$ \\
\hline & $\begin{array}{l}\text { Urinvolumen } \\
\text { (m1/d) }\end{array}$ & $\begin{array}{l}8 \\
\$ \\
\text { ge- } \\
\text { samt }\end{array}$ & $\begin{array}{l}1433 \\
1105 \\
\left.1307^{*}\right)\end{array}$ & $\begin{array}{l}471,2 \\
344,0 \\
455,0\end{array}$ & $\begin{array}{l}491-2375 \\
417-1793 \\
397-2217\end{array}$ \\
\hline
\end{tabular}
chung.

*) Mittelwerte Männer/Frauen im t-Test mit $p<0,01$ differierend. CLRS = Clearance $[\mathrm{ml} / \mathrm{s}], \quad$ CLRM = Clearance bezogen auf Standardkörperoberfläche vọn $1,73 \mathrm{~m}^{2} /$ individa. Körperöberfläche $[\mathrm{ml} / \mathrm{s}]$. 
mittelwert und die Standardabweichung der Kenngrößen berechnet werden (Tab. 3). Die Jahresmittelwerte der Frauen und Männer waren für die Konzentration des Harnstoffs und Kreatinins im Serum, für die Ausscheidung der Metabolite mit dem Urin, sowie für die Kreatinin-Clearance (CLRS) mit $p \leqslant 0,01$ im t-Test signifikant verschieden. Eine Geschlechtsabhängigkeit ergab sich für die Harnstoff-Clearance und für die Kreatinin-Clearance bezogen auf die Standard-Körperoberfläche von $1,73 \mathrm{~m}^{2}\left(\mathrm{CLRM}=\mathrm{CLRS} \times 1,73 \mathrm{~m}^{2} /\right.$ individ. Körperoberfläche in $\mathrm{m}^{2}$ ) nicht.

Die mittlere intraindividuelle (longitudinale) Variation des Serum-Harnstoffs betrug 16,7\%, die des Kreatinins 6,7\% (Tab. 4), während die interindividuelle (transversale) Variation des Harnstoffs um den Faktor 1,3, die des Kreatinins um 2,1 größer war (Tab. 5).

Die Langzeitvarianz über ein Jahr ist bis auf die interindividuelle des Harnstoffs und Kreatinins im Serum je- weils größer als diejenige der beiden Einzelwochen (Woche 1: Mai, Woche 2: November). Auffallend ist die deutlich höhere longitudinale Streuung der Ausscheidungsmengen des Harnstoffs im Urin, sowie der Harnstoff-Clearance in der Mai-Woche gegenüber der Novemberwoche bei den Frauen. Hierbei wird die größere Varianz der Clearance durch diejenige des Urinvolumens und des Harnstoffs bedingt.

Ein entgegengesetztes Verhalten zeigen diese KenngröBen bei Männern. Die Wochendifferenz ist hier geringer, so daß sich fast keine Auswirkung auf die Clearance ergibt.

Durch den Quotienten aus intra-/interindividueller Varianz läßt sich abschätzen, ob der konventionelle Referenzbereich empfindlich genug ist, um bei einem einzelnen Probanden im Krankenheitsfall eine signifikante Änderung einer klinisch-chemischen Kenngröße sicher zu erfassen $(9,10)$. Bei einem Quotienten unter 0,6 ist für

Tab. 4. Mittlere intraindividuelle (longitudinale) Variation (VK\%).

\begin{tabular}{|c|c|c|c|c|c|c|c|c|c|c|}
\hline & \multirow[t]{2}{*}{ Kenngröße } & \multicolumn{3}{|l|}{ Jahr } & \multicolumn{3}{|c|}{ Woche 1} & \multicolumn{3}{|c|}{ Woche 2} \\
\hline & & $\delta$ & 9 & gesamt & o & 9 & gesamt & $\delta$ & 8 & gesamt \\
\hline Serum & $\begin{array}{l}\text { Harnstoff } \\
\text { Kreatinin }\end{array}$ & $\begin{array}{c}20,0 \\
7,01\end{array}$ & $\begin{array}{c}16,2 \\
6,11\end{array}$ & $\begin{array}{c}16,7 \\
6,69\end{array}$ & $\begin{array}{c}11,0 \\
5,97\end{array}$ & $\begin{array}{c}11,4 \\
5,44\end{array}$ & $\begin{array}{c}11,1 \\
5,77\end{array}$ & $\begin{array}{r}15,1 \\
5,99\end{array}$ & $\begin{array}{c}13,1 \\
5,08\end{array}$ & $\begin{array}{c}14,3 \\
5,64\end{array}$ \\
\hline \multirow[t]{6}{*}{ Urin } & $\begin{array}{l}\text { Harnstoff } \\
\text { Kreatinin } / \mathrm{m}^{2} \\
\text { Körperoberfläche }\end{array}$ & $\begin{array}{l}29,6 \\
24,2\end{array}$ & $\begin{array}{l}31,5 \\
18,7\end{array}$ & $\begin{array}{l}30,3 \\
22,2\end{array}$ & $\begin{array}{l}17,8 \\
17,7\end{array}$ & $\begin{array}{l}21,2 \\
16,4\end{array}$ & $\begin{array}{l}19,1 \\
17,2\end{array}$ & $\begin{array}{l}22,8 \\
18,5\end{array}$ & $\begin{array}{l}16,6 \\
15,5\end{array}$ & $\begin{array}{l}20,3 \\
17,3\end{array}$ \\
\hline & $\begin{array}{l}\text { CLRS } \\
\text { Harnstoff }\end{array}$ & 31,5 & 32,5 & 31,9 & 21,3 & 25,0 & 22,7 & 22,9 & 17,4 & 20,7 \\
\hline & $\begin{array}{l}\text { CLRS } \\
\text { Kreatinin }\end{array}$ & 26,2 & 20,7 & 24,2 & 19,2 & 16,2 & 18,0 & 20,0 & 15,0 & 18,0 \\
\hline & $\begin{array}{l}\text { CLRM } \\
\text { Harnstoff }\end{array}$ & 31,5 & 32,4 & 31,8 & 21,2 & 24,7 & 22,5 & 22,9 & 17,5 & 20,8 \\
\hline & $\begin{array}{l}\text { CLRM } \\
\text { Kreatinin }\end{array}$ & 26,5 & 20,9 & 24,5 & 19,1 & 16,3 & 18,0 & 19,1 & 14,7 & 17,4 \\
\hline & Urinvolumen & 25,9 & 27,0 & 25,2 & 21,3 & 24,7 & 22,6 & 28,0 & 15,0 & 22,9 \\
\hline
\end{tabular}

Tab. 5. Interindividuelle (transversale) Variation (VK \%).

\begin{tabular}{|c|c|c|c|c|c|c|c|c|c|c|}
\hline & \multirow[t]{2}{*}{ Kenngröße } & \multicolumn{3}{|l|}{ Jạhr } & \multicolumn{3}{|c|}{ Woche 1} & \multicolumn{3}{|c|}{ Woche 2} \\
\hline & & 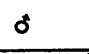 & 8 & gesamt & $\delta$ & 9 & gesamt & $\delta$ & 9 & gesamt \\
\hline Serum & $\begin{array}{l}\text { Harnstoff } \\
\text { Krẹatinin }\end{array}$ & $\begin{array}{l}20,9 \\
11,0\end{array}$ & $\begin{array}{l}21,3 \\
11,9\end{array}$ & $\begin{array}{l}22,3 \\
14,3\end{array}$ & $\begin{array}{c}16,4 \\
9,85\end{array}$ & $\begin{array}{l}17,7 \\
10,7\end{array}$ & $\begin{array}{l}18,6 \\
14,4\end{array}$ & $\begin{array}{l}23,4 \\
11,8\end{array}$ & $\begin{array}{l}18,7 \\
10,4\end{array}$ & $\begin{array}{l}26,0 \\
14,1\end{array}$ \\
\hline \multirow[t]{6}{*}{ Urin } & $\begin{array}{l}\text { Harnstoff } \\
\text { Krẹatinin } / \mathrm{m}^{2} \\
\text { Körperoberfläche }\end{array}$ & $\begin{array}{l}35,3 \\
30,6\end{array}$ & $\begin{array}{l}32,2 \\
20,5\end{array}$ & $\begin{array}{l}33,4 \\
33,4\end{array}$ & $\begin{array}{l}27,7 \\
23,1\end{array}$ & $\begin{array}{l}23,3 \\
17,8\end{array}$ & $\begin{array}{l}29,2 \\
27,9\end{array}$ & $\begin{array}{l}31,6 \\
24,4\end{array}$ & $\begin{array}{l}23,7 \\
19,0\end{array}$ & $\begin{array}{l}32,1 \\
28,5\end{array}$ \\
\hline & $\begin{array}{l}\text { CLRS } \\
\text { Harnstoff }\end{array}$ & 37,5 & 34,4 & 36,5 & 29,4 & 31,1 & 30,2 & 29,4 & 23,4 & 28,5 \\
\hline & $\begin{array}{l}\text { CLRS } \\
\text { Kreatinin }\end{array}$ & 30,4 & 24,3 & 29,9 & 24,2 & 18,0 & 23,9 & 25,6 & 22,8 & 26,1 \\
\hline & $\begin{array}{l}\text { CLRM } \\
\text { Harnstoff }\end{array}$ & 36,2 & 34,9 & 36,7 & 30,0 & 31,2 & 30,5 & 31,4 & 22,6 & 28,3 \\
\hline & $\begin{array}{l}\text { CLRM } \\
\text { Kreatinin }\end{array}$ & 30,1 & 24,6 & 28,3 & 23,6 & 18,6 & 21,8 & 25,1 & 22,3 & 24,0 \\
\hline & Urinvolumen & 32,9 & 31,1 & 34,8 & 33,1 & 35,8 & 36,4 & 37,9 & 34,1 & 41,9 \\
\hline
\end{tabular}


entsprechende Fragestellungen der individuelle Normwert dem Referenzbereich des Gesamtkollektivs vorzuziehen. Dieses Kriterium ist für die Kreatininkonzentration im Serum erfüllt (Tab. 6). Die Kreatininkonzentration im Serum wird individuell in sehr engen Grenzen konstant gehalten (Abb. 1), während die Harnstoffkonzentration durch ihre bekannte Abhängigkeit von der Eiweißzufuhr über einen wesentlich breiteren Bereich schwankt (Abb. 2). Dernentsprechend sind auch interindividuell beim Kreatinin im Serum kaum saisonale Schwankungen zu beobachten (Abb. 3). Das Kreatinin blieb bis auf die Monate Februar mit $-6,8 \%$ und Juli mit $+5,8 \%$ in einem engen Band von $\pm 2 \%$ um den transversalen Jahresmittelwert streuend konstant. Varianz-

Tab. 6. Quotient aus intraindividueller und interindividueller Variation pro Jahr.

\begin{tabular}{lllll}
\hline & Kenngröße & \multicolumn{2}{l}{ Quotient } & \\
& & $\delta$ & $\&$ & gesamt \\
\hline \multirow{2}{*}{ Serum } & Harnstoff & 0,96 & 0,76 & 0,75 \\
\multirow{4}{*}{ Urin } & Kreatinin & 0,64 & 0,51 & 0,47 \\
& Harnstoff & 0,84 & 0,98 & 0,83 \\
& Kreatinin & 0,80 & 0,91 & 0,66 \\
& CLRM & & & \\
& Harnstoff & 0,87 & 0,93 & 1,12 \\
& CLRM & & & \\
& Kreatinin & 0,88 & 0,67 & 0,87 \\
\hline
\end{tabular}

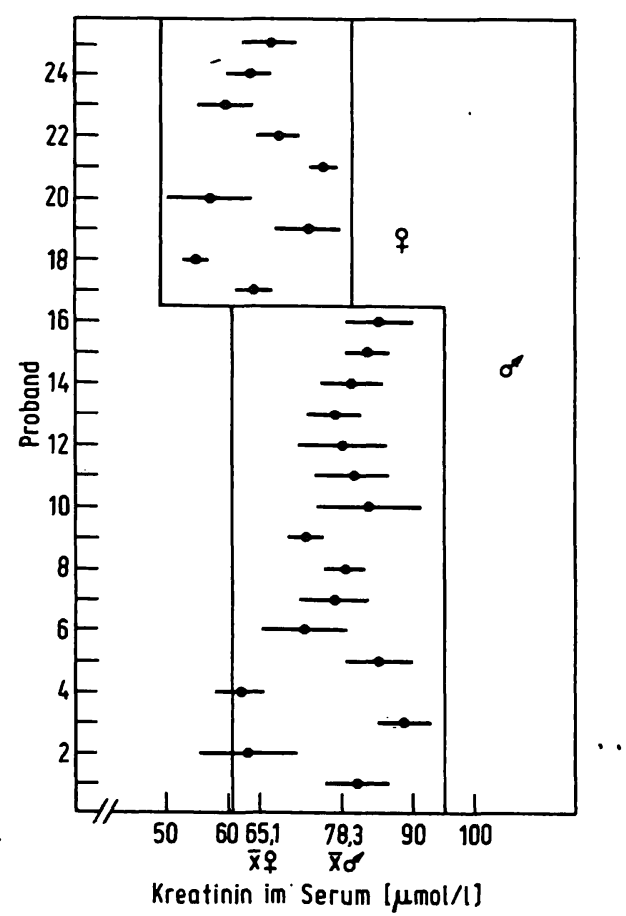

Abb. 1. Intraindividuelle Jahres-Mittelwerte und Variation ( $\pm 2 \mathrm{~s})$ des Kreatinins im Serum ( $n=25$ Probanden, 1-16 Männer, 17-25 Frauen) sowie Jahresmittelwerte und 2-s-Bereich des Kollektivs der Männer und Frauen.

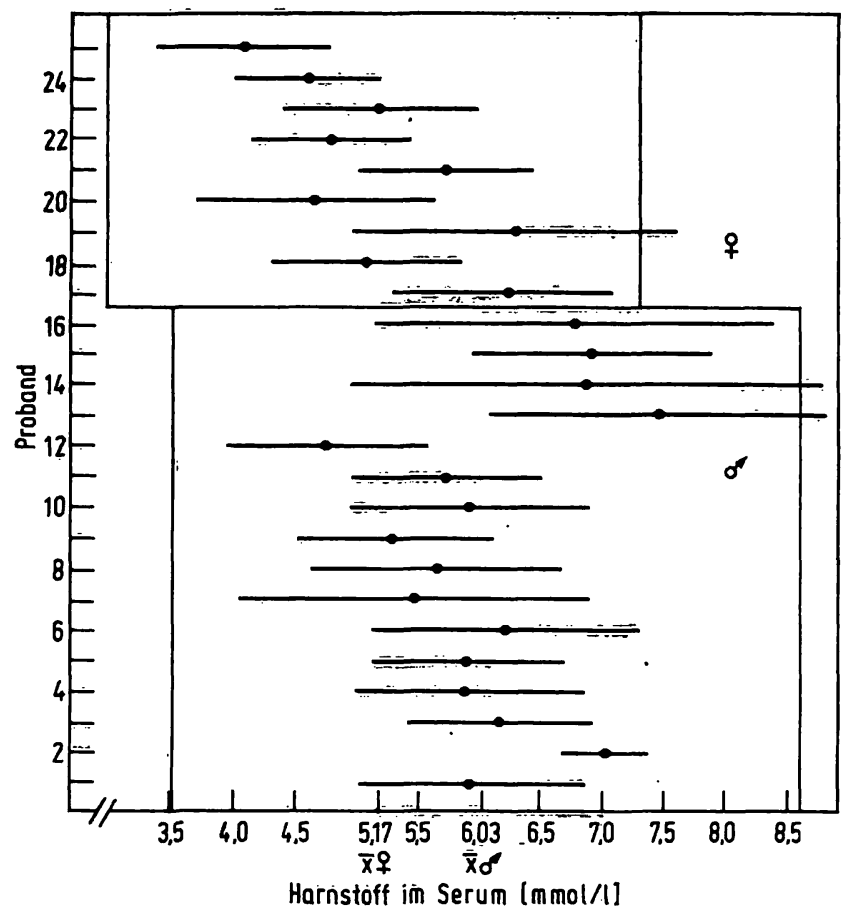

$A b b .2$. Intraindividuelle Jahres-Mittelwerte und Variation $( \pm 2 s)$ des Harnstoffs im Serum ( $n=25$ Probanden, 1-16 Männer, 17-25 Frauen) sowie Jahresmittelwert und 2-s-Bereich des Kollektivs der Männer und Frauen.

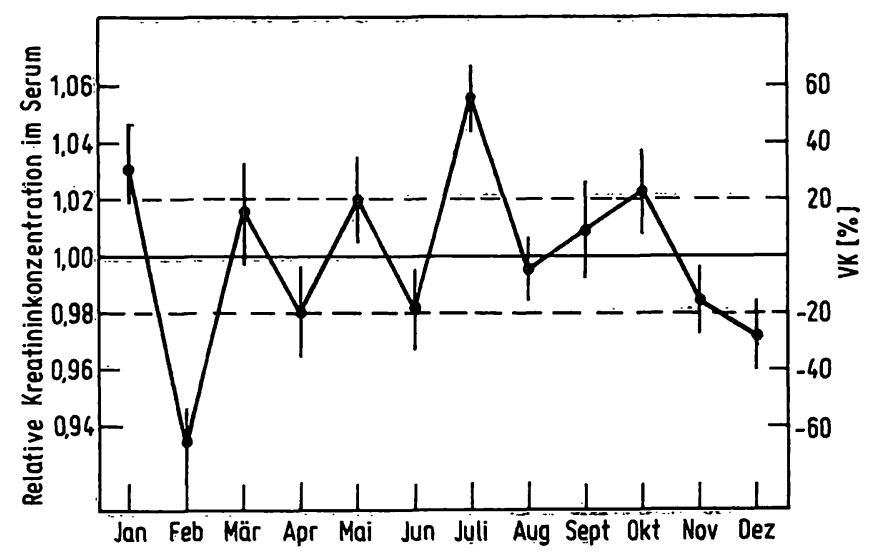

Abb. 3. Jahreszeitliche Schwankungen der interindividuellen Monatsmittelwerte für Kreatinin im Serum ( $n=25$ Probanden) ( \pm 2-s-Bereich) um den Jahresmittelwert (interindividueller Mittelwert $=1,0$ ) unter Korrektur der $\mathbf{A b}$ weichung des mittleren Monats-Istwertes $(n=15)$ des Qualitätskontrollserums vom Sollwert (Tab. 2).

analytisch erwiesen sich die jahreszeitlichen Schwankungen der Kreatinin-Konzentration als nicht signifikant. Diesem Ergebnis entspricht die erstmals von Popper et al. 1938 mitgeteilte Beobachtung über die Konstanz der Kreatininkonzentration im Serum (11). Im Gegensatz zur Kreatinin-Konzentration zeigte diejenige des Harnstoffs im Serum (Abb. 4) eine ausgeprägte jahreszeitliche Schwankung. Die höchsten Konzentrationen wurden im Januar $(+11,4 \%)$, die tiefsten Werte im Mai $(-7,8 \%)$ und September $(-9,7 \%)$ beobachtet. In den übrigen Monaten waren Abweichungen vom Jahresmittelwert um $\pm 6 \%$ festzustellen. 


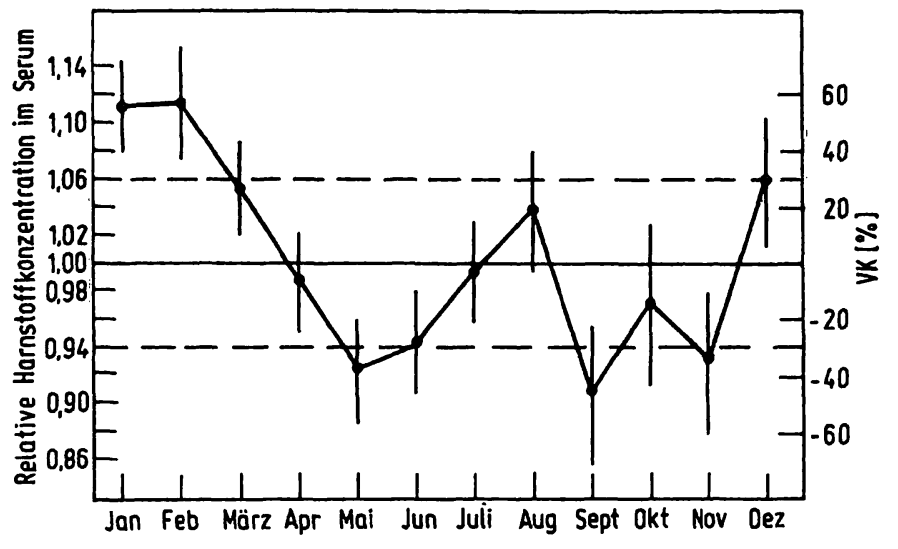

Abb. 4. Jahreszeitlicher Verlauf der Konzentration von Harnstoff im Serum (Darstellung wie Abb. 3).

In der Varianzanalyse erwies sich mit 95\%iger Wahrscheinlichkeit die Differenz zwischen den Monaten Februar und September als signifikant verschieden. Die mittlere Harnstoffkonzentration im Serum lag im Januar gegenüber dem September gerade unterhalb der Signifikanzgrenze.

Auffallend ist, daß die transversale Streuung der Analysenergebnisse in den einzelnen Monaten weitgehend konstant blieb. Es läßt sich vermuten, daß der Jahresverlauf der Harnstoff-Konzentration unterschiedliche Ernährungsgewohnheiten in der kalten und warmen Jahreszeit widerspiegelt.

Als Hauptfehler bei der Bestimmung der Clearance wird unter anderem von Bartels (12) das unvollständige Sammeln des Harns genannt. Im untersuchten Kollektiv betrug die mittlere longitudinale und transversale Variation der Jahresmittelwerte des Urinvolumens žwischen 25 und 35\% (Tab. 4, 5). Auch die Streuung in den einzelnen Monaten lag in entsprechender Größenordnung. In der Varianz sind Einflüsse wechselnder Trinkmengen, Sammelfehler und Volumenmeßfehler subsummiert, da das 24-Stunden-Urinvolumen entsprechend dem klinischen Vorgehen nur auf $50 \mathrm{ml}$ genau gemessen worden ist.

Die Varianzen sprechen für eine Gleichmäßigkeit des Urinsammelns im Kollektiv. Der jahreszeitliche Verlauf mit den niedrigsten Urinvolumina im Winter (Männer $1200 \mathrm{ml} / 24 \mathrm{~h}$, Fraụen $850 \mathrm{ml} / 24 \mathrm{~h}$ im Jänuar), den höchsten in den Sommermonaten (Männer $1550 \mathrm{ml} /$ $24 \mathrm{~h}$, Frauen $1200 \mathrm{ml} / 24 \mathrm{~h}$ im August bzw. September) läßt sich auf jahreszeit-abhängige unterschiedliche Trinkgewohnheiten zurückführen (Abb. 5). Die beobachteten Jahresschwankungen erwiesen sich in der Varianzanalyse als nicht signifikant.

Die mittlere Harnstoffausscheidung von Männern: Frauen betrug 1,3:1,0, die Clearance (CLRS) 1,04:1,00, nach Korrektur auf đie Körperoberfläche (CLRM) 0,92:1,00 (Tab. 3). Die inter- und intraindividuelle Variation betrug $30-36 \%$ (Tab. 4, 5). Wegen Ungleichheit der Varianzen im Gesamtkollektiv ergab sich varianzanalytisch die Notwendigkeit, für den Jahresverlauf das Kollektiv der Männer und Frauen getrennt zu betrachten (Abb. 6). Die Harnstoff-Ausscheidung und -Clearance zeigte ausgeprägte, weitgehend synchrone Schwankungen bei beiden Geschlechtern. Die Minima und Maxima differierten um 50,1-102,4\% im Jahresverlauf (Tab. 7). In der Varianzanalyse erwies sich die Jahresschwankung der Harnstoffausscheidung der

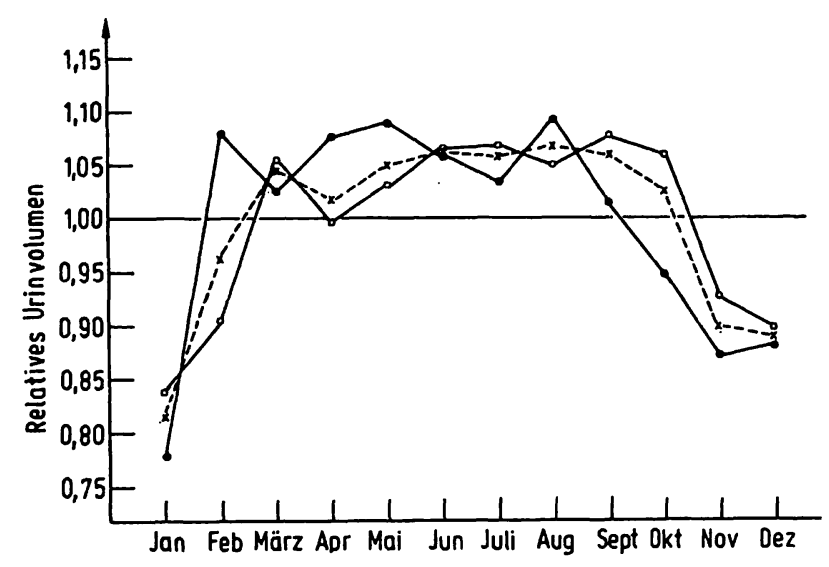

Abb. 5. Jahreszeitliche Schwankungen der interindividuellen Urinvolumen-Mittelwerte um den Jahresmittelwert des Gesamtkollektivs $(x-x)$ sowie der Männer ( $\square-\square$, $n=16)$ und Frauen $(\bullet-, n=9)$. (Darstellung wie Abb. 3).

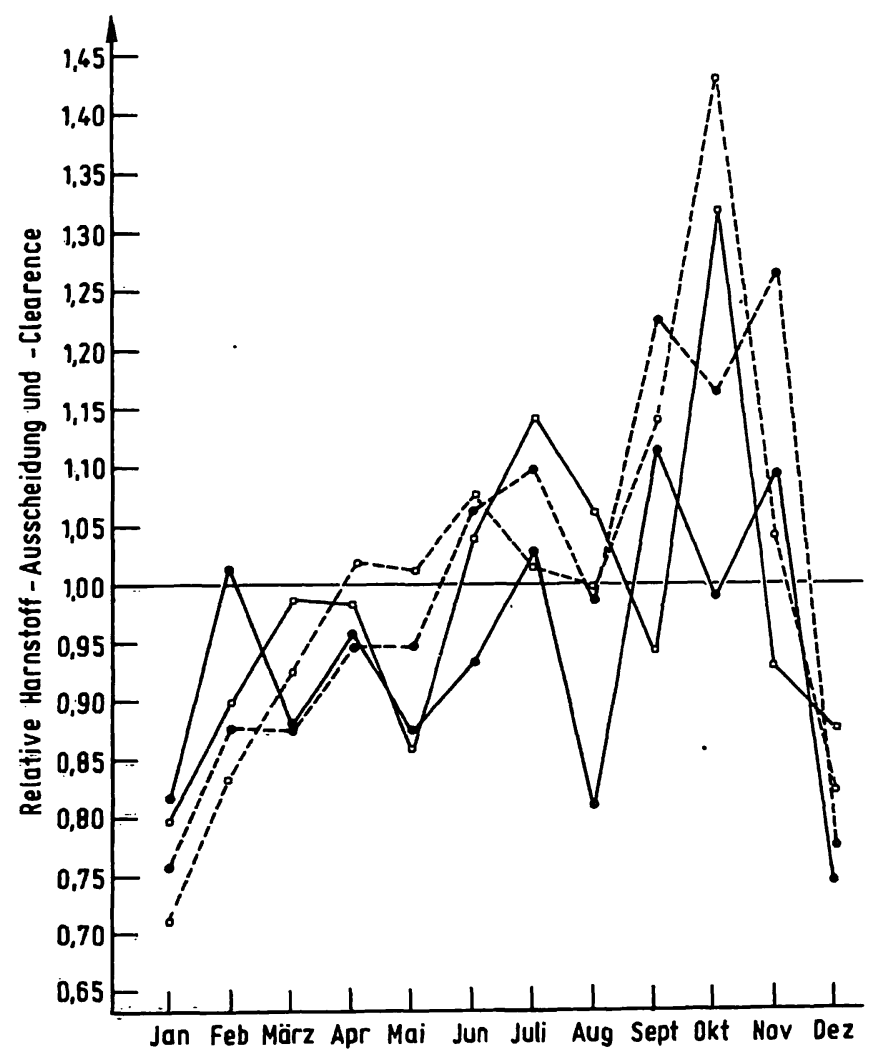

Abb. 6. Jahreszeitlicher Verlauf der Harnstoff-Ausscheidung $(-)$ und der Clearance (--), bezogen auf Körperoberfläche, unter Korrektur des methodischen Trends der Harnstoffbestimmung in den Monaten (entsprechend Abb. 3). $a=\delta, \bullet=8$. 
Tab. 7. Minima und Maxima der Ausscheidung und Clearance (CLRM) von Kreatinin sowie Harnstoff im Jahresverlauf.

\begin{tabular}{|c|c|c|c|c|c|}
\hline & \multirow{2}{*}{$\begin{array}{l}\text { Mittel- } \\
\text { werte }\end{array}$} & \multicolumn{2}{|c|}{ Männer (n = 16) } & \multicolumn{2}{|c|}{ Frauen $(n=9)$} \\
\hline & & $\begin{array}{l}\text { Maxi- } \\
\text { mum }\end{array}$ & $\begin{array}{l}\text { Mini- } \\
\text { mum }\end{array}$ & $\begin{array}{l}\text { Maxi- } \\
\text { mum }\end{array}$ & $\begin{array}{l}\text { Mini- } \\
\text { mum }\end{array}$ \\
\hline \multirow[t]{4}{*}{$\begin{array}{l}\text { Harn- } \\
\text { stoff }\end{array}$} & $\begin{array}{l}\text { Aus- } \\
\text { scheidung } \\
\text { (mmol/l) }\end{array}$ & 465,9 & 260,2 & 307,5 & 204,9 \\
\hline & Differenz & \multicolumn{2}{|c|}{$(79,1 \%)$} & \multicolumn{2}{|c|}{$(50,1 \%)$} \\
\hline & $\begin{array}{l}\text { CLRM } \\
(\mathrm{ml} / \mathrm{s})\end{array}$ & 0,83 & 0,41 & 0,80 & 0,48 \\
\hline & Differenz & $(102$, & & $(66$, & \\
\hline \multirow[t]{4}{*}{$\begin{array}{l}\text { Kreati- } \\
\text { nin }\end{array}$} & $\begin{array}{l}\text { Aus- } \\
\text { scheidung } \\
\text { (mmol/l) }\end{array}$ & 16,72 & 11,44 & 11,53 & 8,26 \\
\hline & Differenz & \multicolumn{2}{|c|}{$(46,2 \%)$} & \multicolumn{2}{|c|}{$(39,6 \%)$} \\
\hline & $\begin{array}{l}\text { CLRM } \\
(\mathrm{ml} / \mathrm{s})\end{array}$ & 2,34 & 1,56 & 2,22 & 1,50 \\
\hline & Differenz & \multicolumn{2}{|c|}{$(50,0 \%)$} & \multicolumn{2}{|c|}{$(48,0 \%)$} \\
\hline
\end{tabular}

Frauen als nicht signifikant, während die Ausscheidung der Männer sowie die Clearance (CLRM) in beiden Geschlechtern signifikante Monatsunterschiede ergab (Abb. 8).

Aus dem Primärharn diffundiert etwa $40 \%$ des glomerulär ausgeschiedenen Harnstoffs parallel zur Wasserreabsorption zurück. Die Harnstoffausscheidung variiert deshalb mit dem Urinvolumen. Die Konzentration im Serum wird neben der Klärrate jedoch überwiegend von der Eiweißzufuhr beeinflußt (13). Dementsprechend ließ sich bis auf den Oktober ein weitgehend synchrones Verhalten von Urinvolumen, Harnstoffausscheidung und -Clearance beobachten. Dabei waren die jahreszeitlichen Variationen der Clearance ausgeprägter als die der Ausscheidung. Dies ist erklärlich durch die um den Faktor 50-60 höhere Menge des Harnstoffs im Urin gegenüber dem Serum und durch die Harnstoff-Ausscheidung im Zähler der Clearance-Formel.

Die Abnahme der Clearance im November bis April ist vermutlich durch das niedrige Urinvolumen mit hoher Harnstoff-Rückdiffusion, sowie den signifikant erhöhten Harnstoff im Serum bedingt. In den Monaten Mai bis September war das relativ höchste Urinvolumen zu beobachten. Bei gleichzeitig geringer Eiweißzufuhr ist die Ausscheidung und die Konzentration im Serum jedoch trotzdem niedrig. Die Folge ist, daß die Clearance.zunimmt und diese im Jahresverlauf prozentual die Ausscheidung übersteigt.

Nicht in dieses Schema läßt sich der Monat Oktober einfuggen. Hier war bei einem relativ niedrigen Urinvolumen (größer bei Männern als bei Frauen) eine hohe Ausscheidung (insbesondere für die Männer) und eine niedrige Konzentration im Serum zu beobachten. Durch die hohe
Ausscheidung errechnete sich eine stark positive Abweichung der Clearance vom Jahresmittelwert.

Die mittlere Kreatininausscheidung betrug für Männer:

Frauen $=1,44: 1,00$, nach Korrektur auf die Körperoberfläche 1,27:1,00. Demgegenüber zeigte die Clearance (CLRM) mit 1,04:1,00 keine Geschlechtsdifferenz (Tab. 3). Die intra- und interindividuelle Varianz (Tab. 4,5 ) betrug $22-33 \%$. Sie làg damit nur geringgradig unter derjenigen der Harnstoffausscheidung und -Clearancè. Die Varianzanalyse ergab auch beim UrinKreatinin die Notwendigkeit beide Geschlechter getrennt zu betrachten (Abb. 7).

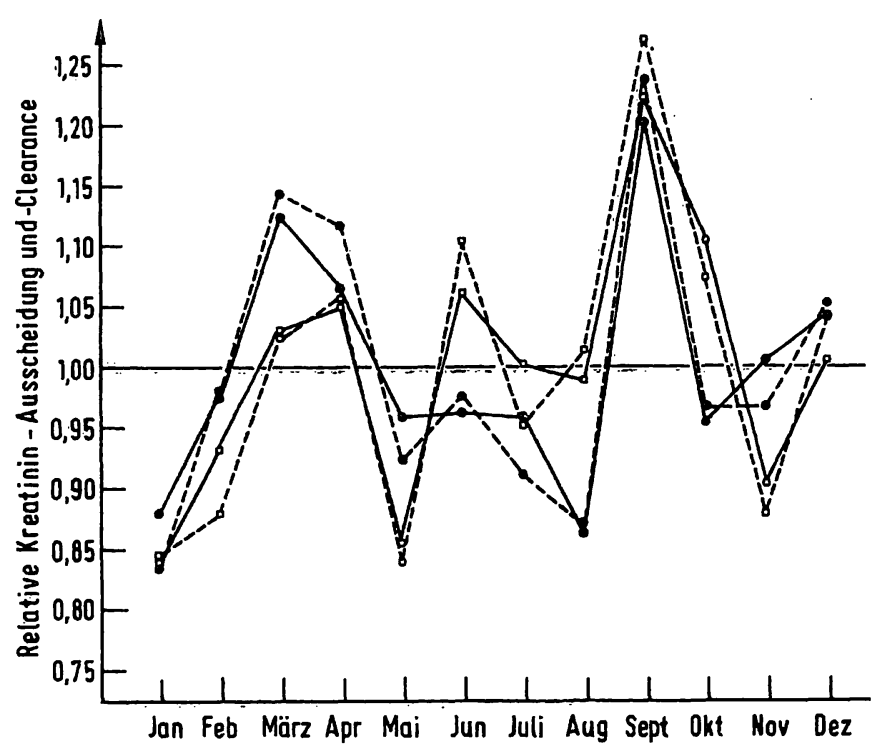

Abb. 7. Jahreszeitlicher Verlauf (Angaben als Fraktionen von $1,0)$ der Kreatinin-Ausscheidung $(-)$ und der Clearance $(--)$, bezogen auf Körperoberfläche, unter Korrektur des methodischen Trends (entsprechend Abb. 3). $\square=\delta$, $\bullet=$ o.

\begin{tabular}{|c|c|c|c|c|}
\hline Monat & Kreatinin & & Harns & toff \\
\hline & $\begin{array}{l}\text { Aus- } \\
\text { scheidung }\end{array}$ & CLRM & $\begin{array}{l}\text { Aus- } \\
\text { schei- } \\
\text { dung }\end{array}$ & CLRM \\
\hline & 9 & 8 & 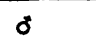 & 8 \\
\hline
\end{tabular}

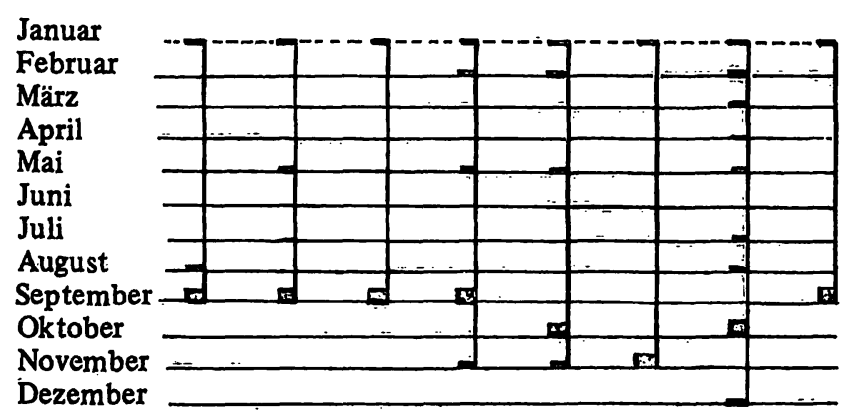

(Keine signifikante Jahresschwankung der Harnstoffausscheidung der Frauen)

Abb. 8. Signifikante Differenzen ( $t-T e s t \cdot p<0,05$ ) der Ausscheidung und Clearance (CLRM) von Kreatinin sowie Harnstoff im Jahresverlauf. 
Die Jahresschwankungen der Kreatinin-Clearance waren ebenso wie die des Harnstoffs größer als die Variation der Ausscheidung. Durch die gegenüber dem Serum im Mittel 160fach höhere Konzentration des Kreatinins im Urin folgt die monatliche Variation der Clearance der Ausscheidung. Die Analysenergebnisse differieren im Gegensatz zum Kreatinin im Serum signifikant in den Monaten (Abb. 8). Das Maximum der Kreatinin-Clearance (CLRM) betrug 2,22 bzw. 2,34 ml/s gegenüber dem Minimum von 1,50 bzw. 1,56 ml/s (Tab. 7). Diese Ergebnisse stehen im Einklang mit denen von Ransil et al.

\section{Literatur}

1. Knoll, E., Wisser, H. \& Rebel, F. C. (1978), J. Clin. Chem. Clin. Biochem. 16, 567-570.

2. Winkel, P. \& Statland, B. E. (1977), in: Contemporary topics in analytical and clinical chemistry. Plenum Press, New York-London, Vol. 1.

3. Robertson, W. G., Hodgkinson, A. \& Marshall, D. H. (1977), Clin. Chim. Acta 80, 347-353.

4. Bartels, H. \& Böhmer, M. (1972), Med. Lab. 26, 209-215.

5. Helger, R., Rindfrey, H. \& Hilgenfeldt, J. (1974), Z. Klin. Chem. Klin. Biochem. 12, 344-349.

6. Koch, C.-D. \& Heimsch, E. (1979), Med. Lab. 32, 33-41.

7. Sachs, L. (1972), Statistische Auswertungsmethoden Springer Verlag, Berlin 3. Aufl.
(14), die gleichfalls saisonale Schwankungen der Kreatininausscheidung beobachteten und widersprechen denen von Robertson et al. (3), die keine signifikanten Differenzen nachweisen konnten.

Die Abweichungen vom Jahresmittelwert verlaufen bei der Ausscheidung bzw. der Clearance von Harnstoff und Kreatinin bis auf die Monate März/April, sowie November/Dezember analog. Dies spricht für eine jahreszeitliche Variabilität der Nierenleistung.
8. Pearson, E. S. \& Stephens, M. A. (1964), Biometrika 51, 484-487.

9. Harris, E. K., Kanofsky, P., Sharkarji, G. \& Cotlove, E. (1970), Clin. Chem. 16, 1022-1027.

10. Harris, E. K. (1974), Clin. Chem. 20, 1536-1542.

11. Popper, H., Mandel, E. \& Mayer, H. (1938), Z. Klin. Med. $133,56-77$

12. Bartels, H. (1972), Med. Welt. 23, 961-963.

13. Kassirer, J. P. (1971), N. Eng. J. Med. 285, 385-389.

14. Ransil, B. J., Greenblatt, D. J. \& Koch-Weser, J. (1977), J. Clin. Pharm. 17, 108-119.

Priv.-Doz. Dr. Claus-Dieter Koch Department fuir Klinische Chemie Universität Ulm

Steinhövelstraße 9

D-7900 Ulm 
